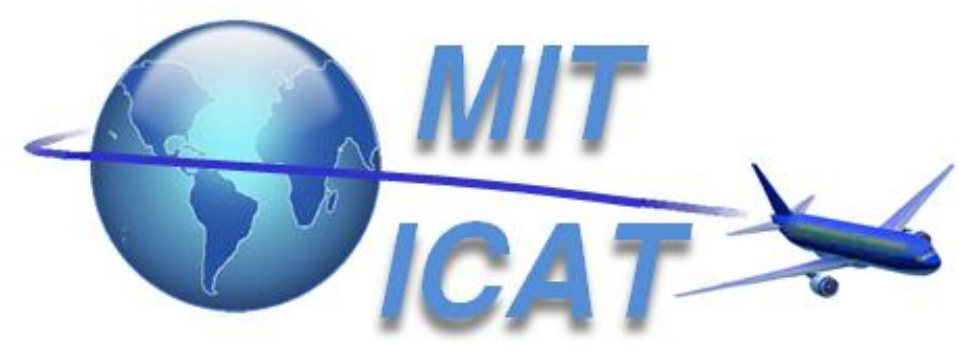

\title{
TRANSITIONING THE U.S. AIR TRANSPORTATION SYSTEM TO HIGHER FUEL COSTS
}

\author{
James K.D. Morrison, Brian Yutko, and R. John Hansman
}

This report is based on the paper prepared for the Transportation Research Board's (TRB) Airport Cooperative Research Program (ACRP) Graduate Research Award Program on PublicSector Aviation Issues.

\section{Report No. ICAT-2011-8}

September 2011

MIT International Center for Air Transportation (ICAT)

Department of Aeronautics \& Astronautics Massachusetts Institute of Technology

Cambridge, MA 02139 USA 
[Page Intentionally Left Blank] 


\title{
Transitioning the U.S. Air Transportation System to Higher Fuel Costs
}

\author{
James K.D. Morrison, Brian Yutko, and R. John Hansman
}

The air transportation system enables economic growth and provides significant social benefits. Future increases and volatility in oil prices, as well as climate change policies, are likely to increase the effective cost of fuel. We investigate the expected impacts of higher fuel costs on the U.S. domestic air transportation system and discuss policy options to reduce negative economic and social effects. The 2004-08 fuel price surge is used as a historical case study. A stochastic simulation model is developed using price elasticity of demand assumptions and flight leg fuel burn estimates to understand the impacts of higher fuel costs. It was found that a $\mathbf{5 0 \%}$ increase in fuel prices is expected to result in a $12 \%$ reduction in ASMs if all cost increases pass through to passengers. System revenues are expected to decrease marginally for fuel price increases up to $\mathbf{5 0 \%}$, but higher increases may result in significant revenue reductions. Small airports are expected to experience relatively larger decreases and greater volatility in traffic. Older aircraft, flying sectors significantly below their optimal fuel efficiency range, are expected to experience the greatest reductions in capacity. An airline case study demonstrates that a regional carrier may be less sensitive to increased fuel prices than other business models. Policy options to maintain small community access, to manage airport traffic volatility, and to improve fleet fuel efficiency are discussed. To transition the U.S. air transportation system to higher fuel costs, stakeholder action will be required.

\section{INTRODUCTION}

The air transportation system is a vital infrastructure that enables economic growth and provides significant social benefits. Future increases and volatility in crude oil prices, as well as climate change policies, are likely to increase the effective cost of fuel. Increased fuel costs may result in changes to supply and demand in

Department of Aeronautics and Astronautics, Massachusetts Institute of Technology, 77 Massachusetts Avenue, Room 33-115, Cambridge, MA 02139.

Corresponding author: J. Morrison, jmorriso@mit.edu the system as passenger travel is suppressed and airlines alter service frequency and network structure. Given the economic and social importance of the air transportation system, stakeholders must understand the impacts of higher fuel costs to design and implement policies that will mitigate negative effects. The purpose of this paper is to investigate the expected impacts of higher fuel costs on the U.S. domestic air transportation system and to discuss policy options to reduce negative economic and social effects.

\section{Motivation}

Climate change policies and oil markets are likely to result in higher effective fuel costs. North American revenue passenger miles (RPM) are forecasted to grow at a rate of $2.8 \%$ p.a. in the $2010-29$ period (1). Historically, aircraft fuel efficiency has improved at a rate of $1.2-2.2 \%$ p.a. (2). Therefore, total $\mathrm{CO}_{2}$ emissions from aviation in the U.S. are expected to continue to grow in the near term. Growing emissions will result in political pressure to take action to reduce aviation's climate change impacts. The International Air Transport Association (IATA) set an average fuel efficiency improvement target of $1.5 \%$ p.a. from 2009 to 2020 (3).

\section{Market-based Mechanisms to Reduce Aviation's Climate Change Impacts}

Market-based mechanisms increase the economic incentive of fuel efficiency improvements by pricing carbon emissions. Price regulations impose taxes on emissions, enabling emitters to choose their optimal emission quantity. Quantity regulations cap the amount of emissions in the economy or sector and assign property rights to emitters in order to create a market price for emission permits. In either type of system, the effective cost of fuel is increased as emitters are forced to pay a price for the climate change impacts of emissions in addition to the jet fuel price.

Aviation will be included in the European Union's Emissions Trading Scheme (ETS) in 2012, putting a price on carbon for all flights with origins or destinations in the E.U. In the United States, the Supreme Court ruled that the Environmental Protection 
Agency (EPA) has the authority and obligation to regulate greenhouse gasses under the Clean Air Act, including $\mathrm{CO}_{2}$ emissions from transportation (4). As other sectors reduce their carbon intensity, pressure will mount for aviation to reduce emissions.

\section{Jet Fuel Prices: Historic Trends and Future Forecasts}

Fuel price volatility increased the past decade. A surge in 2000 resulted in jet fuel prices doubling over 1999 levels. Between July 2004 and July 2008, fuel prices increased $244 \%$ before dropping $50 \%$ by July 2009 . Into 2011, fuel prices were on the rise again. If the world supply of oil decreases and demand does not slacken, fuel prices will continue their upward trend, as predicted by peak oil theorists (5). Without economical, technologically mature, and safety certified energy substitutes, commercial aviation will continue to rely on petroleum based jet fuel at increased prices. The Energy Information Administration's (EIA) reference case forecasts jet fuel prices to reach $\$ 2.97 /$ gallon by 2020 and \$3.41/gallon by 2035 (2010 US\$) without carbon pricing, as shown in Figure 1 (6). The low/high oil scenarios depend on more optimistic/pessimistic assumptions for economic access to non-OPEC resources and for OPEC behavior. In the high price scenario, jet fuel is forecasted to climb to $\$ 4.35 /$ gallon by 2020 and $\$ 5.17 /$ gallon (2010 US\$) by 2035 .

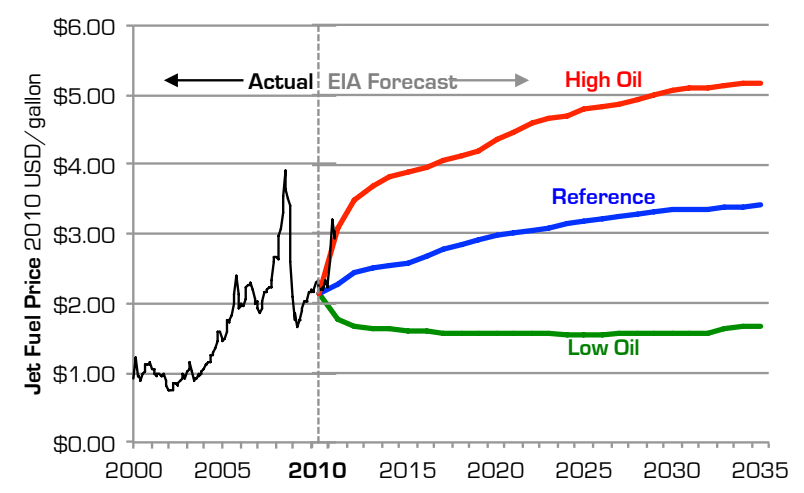

Figure 1 Jet Fuel Price Historical Trends and EIA Future Forecast $[6,7]$.

\section{Objectives and Outline}

Under the expectation of increasing effective fuel costs, whether due to climate change policies or oil markets, the air transportation system will need to transition. To design effective policies that mitigate negative effects, industry stakeholders will need to understand the impacts of higher fuel costs. Section 2 reviews a historical case study on the 2004-08 fuel price surge to gain an empirical understanding of how the system adapted. The complexity of the system and the existence of numerous confounding factors make it difficult to understand the direct impacts of fuel cost increase with an empirical analysis. Section 3 introduces a simulation model that is used to further understanding of the impacts of higher fuel costs on the system in the absence of other, confounding variables. Results from the model under various fuel price scenarios are discussed in Section 4. Potential stakeholder policies to mitigate the expected negative impacts are discussed in Section 5. The paper is summarized and conclusions are drawn in Section 6.

\section{CASE STUDY: 2004-08 FUEL PRICE SURGE}

The cost of jet fuel increased 244\% between July 2004 and July 2008, becoming the largest operating cost item for airlines. Morrison et. al. evaluated how fuel cost increase and volatility affected continental U.S. air transportation networks and fleets in the short- and medium-term using the increase in the 2007-08 and 2004-08 periods as a natural experiment (8). It was found that non-hub airports serving small communities lost $12 \%$ of connections, compared to a sytem average loss of $2.8 \%$, July 2004-08. During the period of sharpest increase, July 2007-08, 70 airports lost all service, resulting in an average driving time of 75 minutes to the next nearest airport with service. It is believed that reduced access to the national air transportation system had social and economic impacts for small communities.

To ensure small communities maintained a link to the national air transportation system, Congress established the Essential Air Service (EAS) program when it passed the Airline Deregulation Act in 1978. EAS provides subsidies to airlines for otherwise unprofitable routes between communities that had air service prior to deregulation and hub airports. A reduction in the financial viability of service to small communities may result in increased government subsidies to commercial aviation in attempts to maintain regional benefits. EAS subsidies jumped from $\$ 50$ million in 2001 to $\$ 176$ million in 2010, providing service to 143 communities nationwide ( 9 ).

In the period of greatest fuel cost increase, July 2007-08, network legacy carriers (NLCs) reduced available seat mile (ASM) supply by $2.8 \%$ while low cost carriers (LCCs) increased ASMs by 5.9\%, capturing greater domestic market share. Regional and commuter carriers without the financial resources to weather the storm were hit hardest, resulting in 10 ceasing operations. Older, less fuel-efficient, and smaller (i.e. 50 or fewer seat) aircraft were parked or retired as airlines reduced the overall number of active aircraft in their fleets by $18 \%$ from Q4 2007-08 (10). 
Collectively, airlines reduced their workforces by about $28,000(7 \%)$ from the end of 2007 to the end of 2008. Airlines relied on ancillary fees (e.g. checked baggage) for $\$ 635$ million of new revenues during the first three quarters of 2008 (10).

During the two periods analyzed by Morrison et. al., airlines were not able to pass the full cost of fuel increase on to passengers (8). Between Q3 2007-08, unit fuel costs increased by $2.20 \notin / A S M$ while unit revenues increased by $0.73 \phi / A S M$. In the medium-term period, Q3 2004-08, unit fuel costs increased 3.57ф while revenue per ASM increased 2.48ф, representing $70 \%$ of the fuel cost increase passed through to passengers.

In the past, some airlines have dampened fuel cost volatility by adopting financial fuel price hedging strategies. The magnitude of the fuel price increase in the 2004-08 period implies that the cost of hedging may increase in the future, accounting for such extremes in volatility. Further, fuel price hedging may not be a viable strategy for permanent fuel cost increases that do not drop soon after the spike. Under permanent increases, airlines may need to alter their networks and fleets to transition to higher fuel costs.

\section{AIR TRANSPORTATION SYSTEM SIMULATION MODEL}

Historical analysis of the U.S. air transportation system has shown that higher fuel costs are likely to impact airline networks and fleets. In this section, a simulation model is developed to further understanding of the expected medium-term impacts of permanent fuel price increase, with other factors held constant.

\section{Model Architecture}

While demand for air transport and capital is derived from the economy, airline activity has direct, indirect, and induced employment effects on the economy. Further, air transportation enables economic growth by providing access to people, markets, ideas and capital (11). Government policy may result in initiatives that increase the effective cost of fuel while at the same time certain policies subsidize essential air service and protect flag carriers. To evaluate first-order impacts of effective fuel cost increase on the air transportation system with all other factors equal, an air transportation system simulation model was developed, as shown in Figure 2.

The economy, fuel prices, and government policy were considered to be external to the model. The model's input variables were determined exogenously while dependent variables were endogenous. To reduce complexity, secondary feedbacks between fuel price and the economy that impact the demand for air transport were not considered. Therefore, given a constant external environment, the expected impacts of effective fuel cost increase on the air transportation system demand, supply, and emissions could be determined. Table 1 shows the indices and variables used to describe the model's equations.

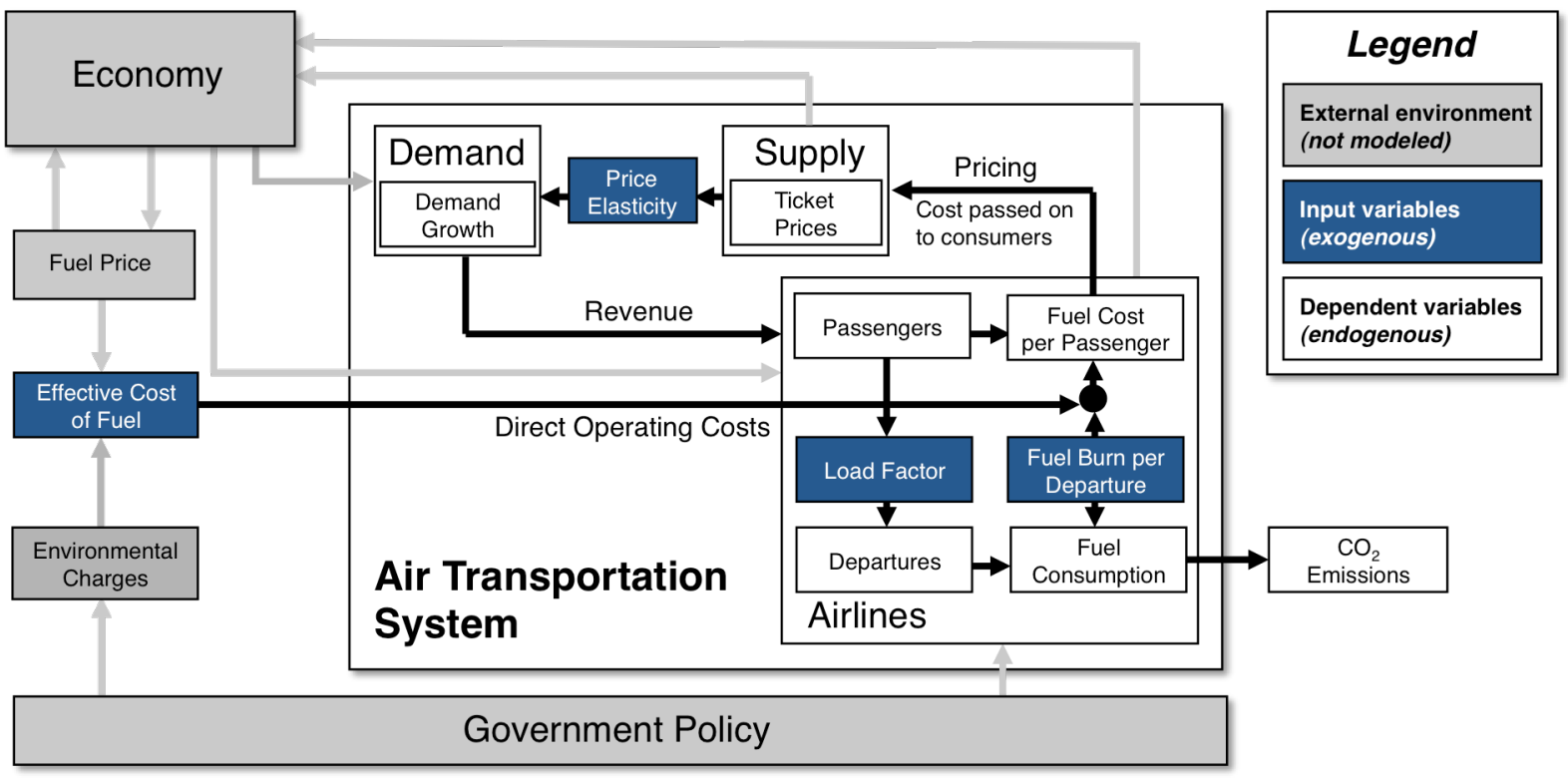

Figure 2 Air Transportation System Simulation Model Architecture. Adapted from 11 and 12. 
Table 1 Air Transportation System Simulation Model Indices and Variables

\begin{tabular}{|c|c|c|c|}
\hline Indices & & & \\
\hline $\begin{array}{l}a \\
\% \\
\end{array}$ & $\begin{array}{l}\text { Aircraft type } \\
\% \text { effective fuel cost increase over base year }\end{array}$ & $i$ & Flight leg \\
\hline \multicolumn{4}{|c|}{ Binary variables } \\
\hline$f$ & Passenger type: business or leisure & $l$ & Stage length: long-haul or short-haul \\
\hline \multicolumn{4}{|c|}{ Input variables } \\
\hline $\begin{array}{l}\eta_{f, l} \\
a_{t p_{i}} \\
l f_{a, i} \\
n_{i, a}\end{array}$ & $\begin{array}{l}\text { Price elasticity of demand } \\
\text { Average leg ticket price } 2010 \text { [US\$] } \\
\text { Load factor } \\
\text { Number of flight legs }\end{array}$ & $\begin{array}{l}p \\
p \% \\
f c_{a, i} \\
e f\end{array}$ & $\begin{array}{l}\text { Average price of fuel in } 2010 \text { [US\$] } \\
\text { Average \% fuel price increase } \\
\text { Flight leg fuel consumption } \\
\text { Emissions factor }[3.15 \mathrm{~kg} \mathrm{CO} / \mathrm{kg} \text { fuel] }\end{array}$ \\
\hline \multicolumn{4}{|c|}{ Dependent variables } \\
\hline $\begin{array}{l}f c p a x_{a, I, \%} \\
f b_{a, i} \\
e\end{array}$ & $\begin{array}{l}\text { Fuel cost increase per passenger [US\$] } \\
\text { Fuel burn [gallons] } \\
\mathrm{CO}_{2} \text { emissions [metric tons] }\end{array}$ & $\begin{array}{l}\operatorname{pax}_{f, a, i} \\
d_{a, i} \\
d g_{f, a, i, \%}\end{array}$ & $\begin{array}{l}\text { Number of passengers } \\
\text { Number of departures } \\
\text { Demand growth }\end{array}$ \\
\hline
\end{tabular}

Market fuel price increases and environmental charges resulting from public policy will result in increases in the effective cost of fuel. We assume that increases in the effective cost of fuel are fully passed on to passengers at a flight leg basis. Therefore, the average fuel cost increase per passenger for a given flight leg can be calculated as the fuel cost increase per passenger, for both business and leisure passengers:

$$
\operatorname{fcpax}_{a, i, \%}=\frac{p * p \% * f c_{a, i}}{\operatorname{pax}_{a, i}}
$$

Although airlines may choose to allocate increases in fuel costs in a different manner for commercial reasons, we assume that airlines will pass the full cost increase on to passengers in order to maintain profitability in the absence of hedging strategies. The pass through of fuel cost increases will impact the demand for air transport. Demand growth from the base case was calculated by employing the price elasticity of demand for each passenger type based on the fuel cost increase per passenger and the average leg ticket price:

$$
d g_{f, a, i, \%}=\eta_{f, l} *\left(\frac{f_{c p a x}^{a, i, \%}}{a t p_{i,}}\right)
$$

The resulting number of passengers on each flight leg was calculated by multiplying the estimated demand growth by the number of passengers in the base year. Holding flight leg load factor and aircraft type constant, the number of departures required to accommodate the estimated number of passengers was determined. System $\mathrm{CO}_{2}$ emissions could then be calculated by summing the fuel consumed by each aircraft type, on each flight leg:

$$
e=\sum_{i=1}^{n_{i}} \sum_{a=1}^{n_{a}} d_{a, i} f c_{a, i} * e f
$$

\section{Input Data and Assumptions}

\section{Data Sources}

Three data sources were used: (1) BTS T100, (2) BTS DB1B, and (3) Piano-X aircraft performance database. The Bureau of Transportation Statistics (BTS) Form 41 Schedule T100 U.S. carrier domestic segment data for the full year 2010 provided the base year operational data (13). Data was filtered to exclude cargo service, military flights, repositioning flights (i.e. departures performed with zero passengers reported), and sightseeing (i.e. departures performed whose origin and destination were the same airport). The BTS Airline Origin and Destination Survey (DB1B) provided a 10\% sample of all domestic airline tickets (13). These data were used to estimate average flight leg airfares and leisure/business passenger splits. Airfares with yields less than \$0.02/RPM were filtered to eliminate frequent flier redemptions. Flight legs with fewer than 100 passengers reported in the $10 \%$ ticket sample were filtered due to their limited statistical significance. The Piano-X aircraft performance database was used to estimate the fuel burn on each flight leg reported in the T100 operational data (14). Piano-X contains performance models for 53 of the 98 aircraft types reported in the 2010 BTS T100 database. These filters resulted in our base year domestic data set containing $98.5 \%$ of ASMs, $90.6 \%$ of departures, and $35.8 \%$ of airports served. The majority of airports and departures excluded were in Alaska or remote areas of continental U.S., served by small piston and turboprop aircraft. 
Table 2 Input Variables and Assumptions

\begin{tabular}{|c|c|c|c|}
\hline Input Variable & Description & Assumptions & Source \\
\hline $\begin{array}{l}\text { Price elasticity of } \\
\text { demand, } \eta_{f, l}\end{array}$ & $\begin{array}{l}\text { Domestic Market Types: } \\
\text { (1) Business/leisure } \\
\text { (2) Long-haul/short-haul }\end{array}$ & $\begin{array}{l}\text { Business, long haul, domestic: } \\
H_{B, L H, D O M} \sim \mathrm{N}(-1.15,0.09) \\
\text { Business, short-haul domestic: } \\
H_{B, S H, I N T} \& \eta_{B, S H, D O M} \sim \mathrm{N}(-0.70,0.01) \\
\text { Leisure, long haul, domestic: } \\
H_{L, L H, D O M} \sim \mathrm{N}(-1.10,0.05) \\
\text { Leisure, short-haul domestic: } \\
\quad H_{L, S H, I N T} \& \eta_{L, S H, D O M} \sim \mathrm{N}(-1.52,0.06)\end{array}$ & $\begin{array}{l}\text { Gillen et al. (15) } \\
\text { BTS DB1B (13) }\end{array}$ \\
\hline $\begin{array}{l}\text { Average ticket } \\
\text { price, } a t p_{i}\end{array}$ & $\begin{array}{l}\text { Average flight leg air fare, } \\
\text { prorated by miles flown }\end{array}$ & $\begin{array}{l}\text { Average business and leisure airfares are } \\
\text { equivalent }\end{array}$ & BTS DB1B (13) \\
\hline Load factor, $l f_{i}$ & Flight leg load factor & Constant base year flight leg load factors & BTS T100 (13) \\
\hline $\begin{array}{l}\text { Fuel burn per } \\
\text { departure, } f b_{i}\end{array}$ & $\begin{array}{l}\text { Flight leg fuel burn } \\
\text { calculated by aircraft type }\end{array}$ & $\begin{array}{l}\text { Fuel efficiency and fleet composition kept } \\
\text { constant. Payload and range taken from } \\
\text { operational data. }\end{array}$ & $\begin{array}{l}\text { BTS T100 (13) } \\
\text { Piano-X }(14)\end{array}$ \\
\hline \multicolumn{4}{|c|}{$\begin{array}{l}\text { Notes: To recognize uncertainty, the price elasticities of demand assumptions were modeled as distributions. } \mathrm{N} \sim\left(\mu, \sigma^{2}\right) \text { indicates a } \\
\text { normal distribution }\left(\mu=\text { expected value, } \sigma^{2}=\text { variance). }\right. \\
\text { (1) Price elasticities of demand: Expected values and the variances were derived from the quartiles in }(15) \text {. } \\
\text { (2) Long-haul/short-haul traffic: Flight legs greater than } 1,500 \text { miles considered long haul. }\end{array}$} \\
\hline
\end{tabular}

\section{Input Variables}

The input variables were price elasticity of demand, average ticket price, load factor, and fuel burn per departure, as summarized in Table 2. To apply the correct price elasticity of demand, a methodology was developed to estimate the breakdown of passenger trip purpose on all flight legs in the domestic system. Although passenger surveys or detailed airline revenue management data would be required to determine the fraction of leisure passengers on every flight in the domestic system, no comprehensive publicly available data set exists. As part of the $10 \%$ ticket sample, BTS publishes itinerary fare class codes, but this data was found to be inappropriate for analysis due to differences in carriers' reporting standards.

Passenger itineraries were used to estimate flight leg business and leisure passenger splits. Imbalances in the number of originating and destination passengers at each airport were used to form airport leisure indices. Airports with a greater number of destination passengers than originating passengers were assumed to attract proportionally more leisure passengers than business passengers. The airport leisure indices were used as a proxy for the fraction of destination leisure passengers at each airport.

The fraction of leisure passengers expected on each flight leg in the system was estimated by summing the airport leisure indices of all passengers' itinerary breakpoints (i.e. destination airport) on each flight leg. This method implicitly assumed that $50 \%$ of path passengers are leisure and $50 \%$ are business. Due to leisure passengers' greater willingness to connect, this method estimated $52 \%$ of enplaned passengers were leisure. The marketing firm JCDecaux publishes aggregated survey data of passenger trip purposes at 19 airports in the U.S. (16). By taking the average fraction of leisure passengers of the airports in the data set, weighted by the airports' annual number of domestic passengers, it was estimated that $59 \%$ of enplaned passengers in the U.S. domestic system are leisure passengers. A linear translation was applied to the estimated fraction of leisure passengers on each flight leg to yield a system average of 59\% leisure passengers.

There is significant uncertainty in both the assignment of passenger type and passenger price elasticity. To recognize this uncertainty, a stochastic Monte Carlo simulation approach was used. The model's dependent variables were calculated by taking the average of 1000 runs. Random draws from each price elasticity of demand distribution were taken for each run. Therefore, the model output parameters are expected values and variances result from the distribution of values over 1000 runs.

Airline revenues are derived from selling tickets for origin-destination markets while costs are incurred for flight legs that contain passengers from multiple origindestination markets. Therefore, assumptions must be made to assign revenues to flight legs or costs to O-D markets. We prorated itinerary airfares to flight legs using miles flown to estimate average ticket prices. This enabled flight leg fuel cost increases as a share of flight leg average ticket prices to be used to calculate demand growth directly using equation 2 .

Fuel consumption for each flight leg in the base year operational data was computed using Piano-X mission simulations. For each aircraft type, missions 
were simulated at fractions of maximum structural payload (MSP) and fractions of $\mathrm{R}_{1}$ range (i.e. the range at which the sum of payload and fuel are limited by the maximum takeoff weight, requiring payload to be traded for range). For each aircraft type, 30 missions were simulated at $1.0 * \mathrm{MSP}, 0.8^{*} \mathrm{MSP}, \ldots, 0 * \mathrm{MSP}$ and $1.0 * \mathrm{R}_{1}, 0.8 * \mathrm{R}_{1}, \ldots, 0.2 * \mathrm{R}_{1}$. Zero wind, ISA atmosphere, staged altitude from FL210 to FL530 (with RVSM from FL290 to FL410), and speed set to max specific air range were assumed for all missions. Passenger weight, taxi times, fuel reserves, and diversion distance assumptions consistent with International Civil Aviation Organization (ICAO) analyses were used to generate realistic mission fuel burn estimates (17). A bi-cubic interpolation algorithm was used to compute aircraft specific mission fuel burn, given BTS T100 operational payload and range data, and the grid of simulated fuel consumption determined using Piano-X.

\section{Model Limitations}

A number of assumptions are built into the model, limiting the types of analysis that it is useful for. The types of aircraft in the fleet are held constant while the utilization of specific types is allowed to change. The same aircraft types serve the same city pairs as in the base year, so aircraft are not reassigned to different sectors. Airlines do not add or remove markets from their networks - they are only able to change frequency of service. When demand drops due to increased ticket prices, we assume that airlines reduce service frequency instead of down gauging aircraft size. No diversion of passengers served by point-to-point flights to hub connecting itineraries is accounted for. We assume $100 \%$ of fuel cost increase is passed on to consumers and that the system adapts instantaneously to a different average fuel price.

In reality, there are a number of important time lags in the air transportation system. Schedules are generally set six to twelve months in advance of departure. Tickets can be sold up to one year in advance of departure, but generally within 60 days. Fuel prices in the past decade have exhibited a high level of volatility characterized by rapid ascents and descents. In the face of rapidly escalating fuel prices, these time delays can force airlines to operate unprofitable flights.

Aircraft leases range from months to years, while aircraft that are owned have average operating lifespans of 20-25 years. In the short-term, the fleet decisions available to airlines are to fly their aircraft or park them. In the medium- and long-terms, airlines have more flexibility. New aircraft enter the fleet (either leased or purchased) and old aircraft exit the fleet (either through lease expiration or retirements).
Given its limitations, the model gives insight to short- and medium-term changes in the air transportation system as it transitions from one fuel price level to another without the ability to implement long-term efficiency measures or significantly alter fleet composition.

\section{RESULTS}

This section highlights results found with the simulation model, categorized by the impacts at: (1) the system level, (2) airports, (3) aircraft, and (4) airlines. System level results are aggregated for the entire U.S. domestic air transportation system, while the remaining sections break down the results for industry stakeholders. Table 3 shows the effective fuel price used for each scenario investigated. The $0 \%$ scenario is the base case, derived from the average fuel price paid by U.S. carriers in 2010 (7).

Table 3 Effective Fuel Price Scenarios Investigated

\begin{tabular}{|c|c|c|c|c|c|c|}
\hline Scenario & $-50 \%$ & $\begin{array}{c}0 \% \\
\text { (Base) }\end{array}$ & $+50 \%$ & $+100 \%$ & $+150 \%$ & $+200 \%$ \\
\hline $\begin{array}{l}\text { Fuel Price } \\
\text { US\$/gallon }\end{array}$ & $\$ 1.12$ & $\$ 2.24$ & $\$ 3.37$ & $\$ 4.49$ & $\$ 5.61$ & $\$ 6$. \\
\hline
\end{tabular}

\section{System}

\section{Demand and Supply}

Increases in effective fuel cost that are passed on to passengers are expected to result in significant reductions in demand and supply in the system. Figure 3 shows that a 50\% increase in fuel price results in a $12 \%$ decrease in demand and supply in the system. A tripling of fuel prices is expected to result in a $49 \%$ reduction in RPMs and ASMs.

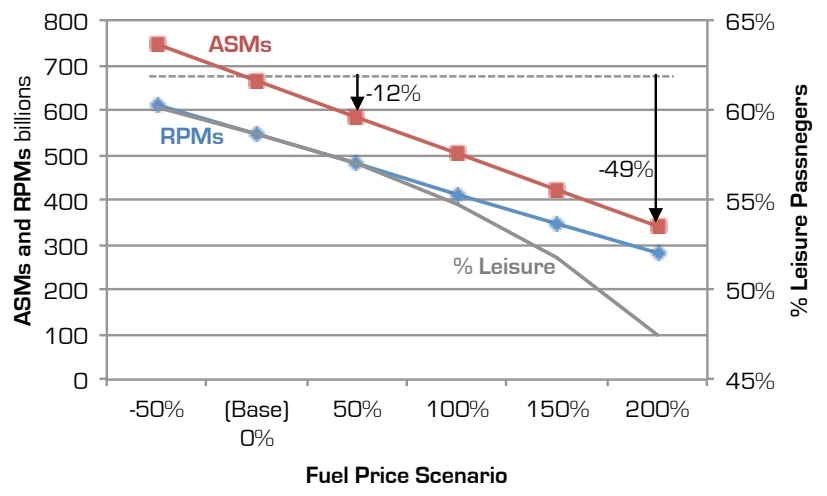

Figure 3 Expected System-wide Demand and Supply 
These relationships are not linear. As fuel prices increase, leisure traffic is more sensitive than business. The share of leisure passengers in the system is expected to drop from $59 \%$ in the base case to $57 \%$ in the $+50 \%$ scenario and $48 \%$ in the $+200 \%$ scenario.

Passengers on long-haul flights are less sensitive to fare increases than passengers on short-haul flights, but fuel represents a greater share of operating costs on long-haul flights than short-haul (18). The model showed that long-haul flights are expected to be more sensitive to fuel price increases. In the $+50 \%$ scenario, the number of short-haul departures dropped $11 \%$ while long-haul departures dropped $13 \%$. In the $+200 \%$ scenario, the number of short-haul departures dropped $44 \%$ while long-haul departures dropped $54 \%$. Systemwide, the number of passengers and departures is expected to drop by $11 \%$ per $50 \%$ fuel price increase.

Airlines are more likely to cut flight legs with low load factors first as the fuel cost increase per passenger is greater than equivalent flight legs with high load factors. This resulted in system-wide average load factors increasing marginally from $82.3 \%$ in the base case to $82.5 \%$ in the $+200 \%$ scenario, despite the model's constant flight leg load factor assumption.

\section{Revenues and Costs}

With moderate fuel price increase (i.e. $<+50 \%$ ) system revenues are expected to remain relatively constant, as higher airfares from fewer passengers are adequate to sustain revenues. Large fuel price increases result in declines in revenues as air travel becomes uneconomical for many passengers and fuel costs require an increasing proportion of revenues, as shown in Figure 4. In the $+50 \%$ scenario, total system fuel costs increase $32 \%$ while revenues drop $2.8 \%$. In the $+200 \%$ scenario, total system fuel costs increase 54\% while revenues drop $25 \%$. In 2010 , system fuel costs were $20 \%$ of revenues, while in the $+200 \%$ scenario fuel costs are expected to reach $40 \%$ of revenues.

This analysis demonstrates that airlines have some flexibility to manage increased fuel prices without severe financial impacts, but dramatically higher fuel prices are likely to have severe impacts on the economic sustainability of the system.

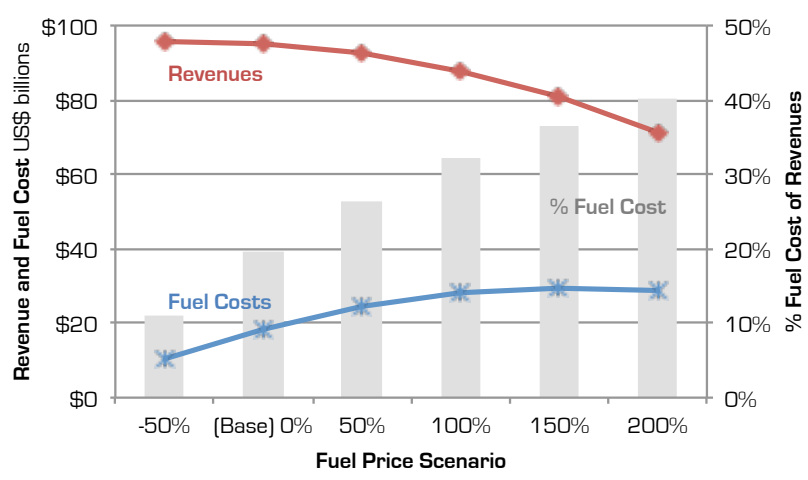

Figure 4 Expected System-wide Revenues and Fuel Costs

\section{Environmental Impacts}

Increased effective fuel costs will provide incentives for airlines to improve fleet fuel efficiency. It is assumed that technologies and operational improvements will not be available to offset fuel price increases in the short- to medium-term examined in this paper. Therefore, improvements in the environmental impacts of aviation come at the expense of mobility. As departures and ASMs decrease, fuel burn and $\mathrm{CO}_{2}$ emissions are reduced. A 50\% fuel price increase results in a $12 \%$ reduction in fuel burn, while a $200 \%$ fuel price increase results in a $49 \%$ decrease in fuel burn. When considering policy options to reduce the climate change impacts of aviation, decision makers will need to consider the economic costs of demand reductions and demand shifts to other modes of transport.

\section{Airports}

Smaller airports are expected to suffer relatively greater reductions in traffic than larger airports. Figure 5 shows the relative change in airport departures in the $+100 \%$ scenario, binned by the average daily airport departures in the base year on a log scale. Airports with less than one daily departure in 2010 are expected to experience a median traffic reduction of $-39 \%$, while the system average is expected to be $-23 \%$. Further, small airports are expected to experience significantly greater volatility in traffic, as exhibited by the $5 \%$ and $95 \%$ ranges of percent change in daily departures. 


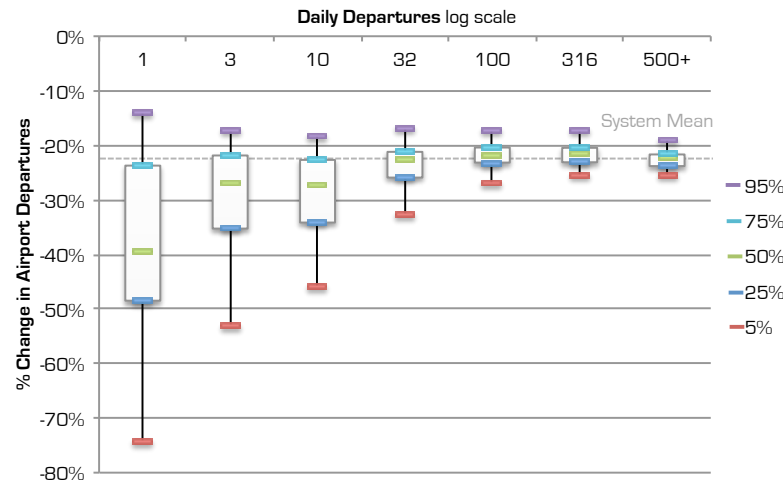

Figure $\mathbf{5}$ Change in Airport Departures by Airport Size +100\% Fuel Price Scenario

Grouping airports by their 2010 FAA airport hub class $^{1}$, non-hub airports are expected to see relatively greater reductions in service than other hub classes. For the $+50 \%$ scenario, non-hub airports lost $13.0 \%$ of departures vs. a system mean of $11.3 \%$. This $1.7 \%$ differential scaled with increased fuel prices. Non-hub airports are expected to lose $5.3 \%$ more departures than the system mean in the $+200 \%$ scenario. In the base case, compared to the system mean, departures from non-hub airports had higher average yields (\$0.299/RPM vs. \$0.174/RPM), a slightly lower average fraction of leisure passengers (56\% vs. 59\%), but were served by smaller aircraft (66 seats vs. 125 seats), that flew shorter stage lengths (303 miles vs. 673 miles $)$, had higher fuel intensity $(0.0153$ gallons/ASM vs. 0.0125 gallons/ASM), and lower load factors $(73 \%$ vs. $82 \%)$.

As service to small airports is reduced, hub-andspoke networks will tend to strengthen. Traffic is expected to become relatively more concentrated on connections between medium and large hubs. Cento (2009) proposed using the Freeman network centrality index to measure the strength of hub-and-spoke vs. point-to-point networks (19). In a pure hub-and-spoke network, all airports are connected through one hub. In a pure point-to-point network, all airports are connected directly to every other airport in the network. The Freeman network centrality index uses the weighted average of paths through each airport connecting every other airport in the network, normalized by the maximum value achieved by a pure hub-and-spoke network. Therefore, for a pure hub-andspoke network the Freeman index is 1, while for a fully connected point-to-point network the Freeman index is 0 . In the base case, the system Freeman index was 0.17 , increasing to 0.23 in the $+100 \%$ and 0.38 in the $+200 \%$ scenarios. Extreme fuel price increases may result in significant strengthening of hub-and-spoke networks in which point-to-point service is no longer economical and a significant number of spoke cities lose service completely.

\section{Aircraft}

Increased fuel prices are expected to have a greater impact on older, less fuel-efficient aircraft types as airlines park or retire inefficient planes. Figure 6 demonstrates that wide body aircraft ASMs are expected to be reduced relatively more than other aircraft types. In the domestic system base case, wide bodied aircraft account for only $7.1 \%$ of ASMs and $6.8 \%$ of fuel burn while narrow bodied aircraft account for $78 \%$ of ASMs and $75 \%$ of fuel burn. Therefore, changes in narrow body aircraft usage have a much greater impact on the system. Older narrow body aircraft types (i.e. 737-200, DC-9, and 727-200) are expected to experience the greatest absolute reductions in ASMs.

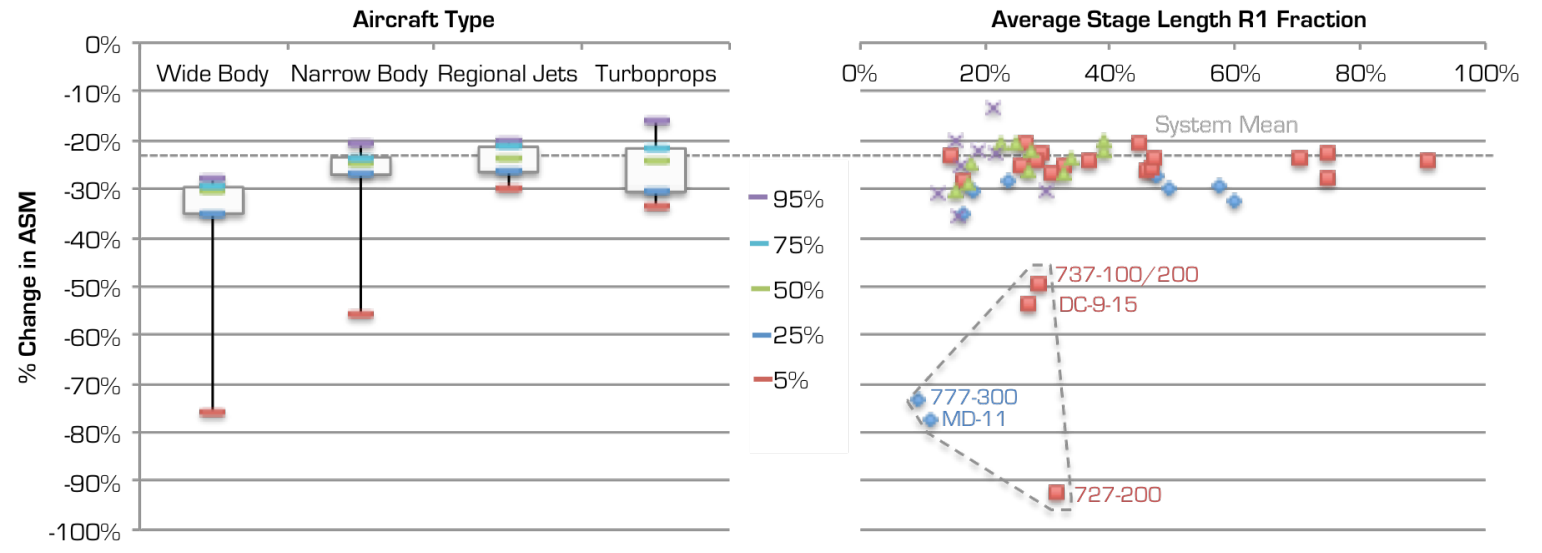

Figure 6 Change in ASMs by Aircraft Type +100\% Fuel Price Scenario

\footnotetext{
${ }^{1}$ The FAA classifies airport hub type by the percentage of system annual passenger boardings at the airport: Large ( $1 \%$ or more), Medium ( $0.25-$ $1 \%)$, Small (0.05-0.25\%), NonHub $(<0.05 \%)$.
} 
Table 4 Representative Airline Statistics Average Domestic Network Statistics

\begin{tabular}{|c|c|c|c|c|c|c|c|c|}
\hline \multirow[t]{2}{*}{ Carrier } & \multicolumn{3}{|c|}{ Domestic Fleet } & \multicolumn{5}{|c|}{ Domestic Network } \\
\hline & No. & $\begin{array}{c}\text { Age } \\
\text { (years) }\end{array}$ & Aircraft & Destinations & $\begin{array}{l}\text { Stage } \\
\text { (miles) }\end{array}$ & $\begin{array}{l}\text { Load } \\
\text { Factor }\end{array}$ & $\begin{array}{c}\% \\
\text { Leisure }\end{array}$ & $\begin{array}{c}\text { Yield } \\
\text { (\$/RPM) }\end{array}$ \\
\hline NLC & 448 & 15.0 & $\begin{array}{l}\text { DC9, MD80, } \\
\text { B737, B757, } \\
\text { B767, B777 }\end{array}$ & 124 & 1067 & $83.2 \%$ & $60 \%$ & $\$ 0.158$ \\
\hline LCC & 113 & 5.4 & A320, E190 & 72 & 994 & $82.1 \%$ & $61 \%$ & $\$ 0.141$ \\
\hline Regional & 178 & 8.5 & $\begin{array}{l}\text { CRJ, E135, } \\
\text { E140, E145 }\end{array}$ & 148 & 465 & $74.6 \%$ & $56 \%$ & $\$ 0.258$ \\
\hline
\end{tabular}

Narrow bodies, regional jets, and turboprops are generally most fuel-efficient operating at their $\mathrm{R}_{1}$ stage lengths. Aircraft operating in sectors with stage lengths significantly less than their $\mathrm{R}_{1}$ range are generally flying missions with reduced fuel efficiencies due to the fixed costs of taxiing, takeoff, landing, and the required fuel reserves. Figure 6 shows that aircraft flying sector stage lengths significantly below their most fuel efficient operating points are expected to experience relatively greater reductions in ASMs.

\section{Airlines}

To test the competitive effects of fuel cost increase on airline business models, the simulation model was run for three representative airlines: (1) a network legacy carrier (NLC), (2) a low cost carrier (LCC), and (3) a regional carrier $(\mathrm{RC})$. Representative statistics for each airline are displayed in Table 4.

Figure 7 shows the relative change in airline ASMs from the system-wide trend in each of the fuel cost scenarios investigated. The LCC is impacted greatest, shedding $13.3 \%$ versus the system average of $11.9 \%$ in the $+50 \%$ scenario. The NLC is also expected to fair worse than the system average, reducing ASMs by $12.5 \%$ in the $+50 \%$ scenario. Although the regional carrier has lower system load factors and stage lengths, the higher yields and lower leisure passenger mix resulted in reductions in ASMs of $11.7 \%$ in the $+50 \%$ scenario, $0.3 \%$ better than the system-wide average. These trends carried forward through all of the fuel price scenarios investigated.

Due to the LCCs younger fleet, its average fuel intensity was 0.011 gallons/ASM, while the NLC fuel intensity was 0.012 gallons/ASM. The regional carrier's smaller aircraft and shorter stage lengths resulted in an average fuel intensity of 0.017 gallons/ASM. It could be expected that the less fuelefficient regional carrier would suffer more from increased fuel prices, but the airline's passenger mix offsets its relatively higher fuel intensity. The NLC and LCC share of leisure passengers dropped from $60 \%$ and $61 \%$ in the base case to $48 \%$ and $49 \%$ in the $+200 \%$ scenario, while the regional carrier's share of leisure passengers dropped from $56 \%$ to $41 \%$. Therefore, differences in airline network structures and leisure/business passenger mix have important consequences when evaluating the expected impacts of increased fuel prices.

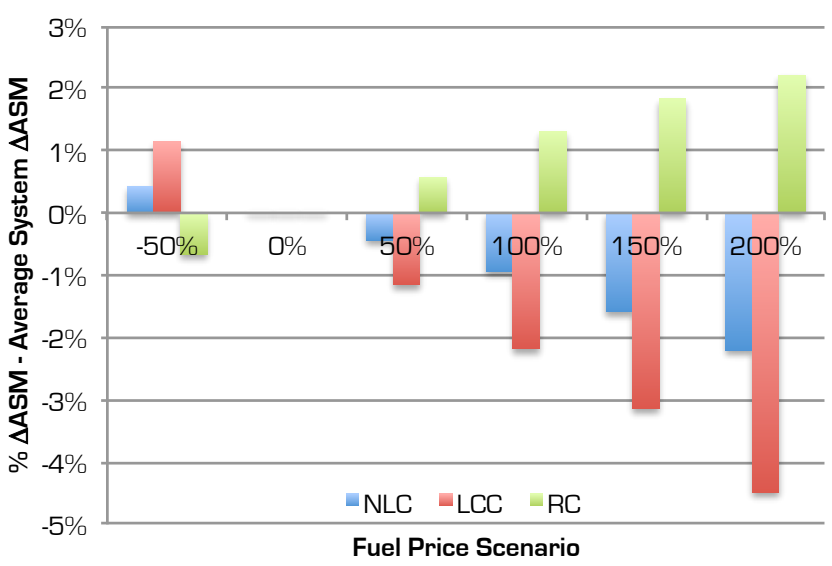

Figure 7 Relative Changes in Airline ASMs from System Average Change

\section{Sensitivity Analysis}

The simulation model results are highly dependent on the input parameters and the model's assumptions. Figure 8 shows the sensitivity of system ASMs to each of the input parameters altered by plus or minus $10 \%$ of their initial values. The expected ASM supply in the system is most sensitive to the flight leg airfare and fuel burn assumptions. The results are less sensitive to the mean price elasticity of demand assumptions and the assumed distribution of leisure passengers on flight legs. System revenues were found to change by $11 \%$ with a $10 \%$ change in the base airfares (not shown). The short-haul leisure passenger price elasticity of demand assumption had the next greatest impact on revenues, resulting in a $1.5 \%$ change in revenues with a $10 \%$ change in the mean elasticity. 


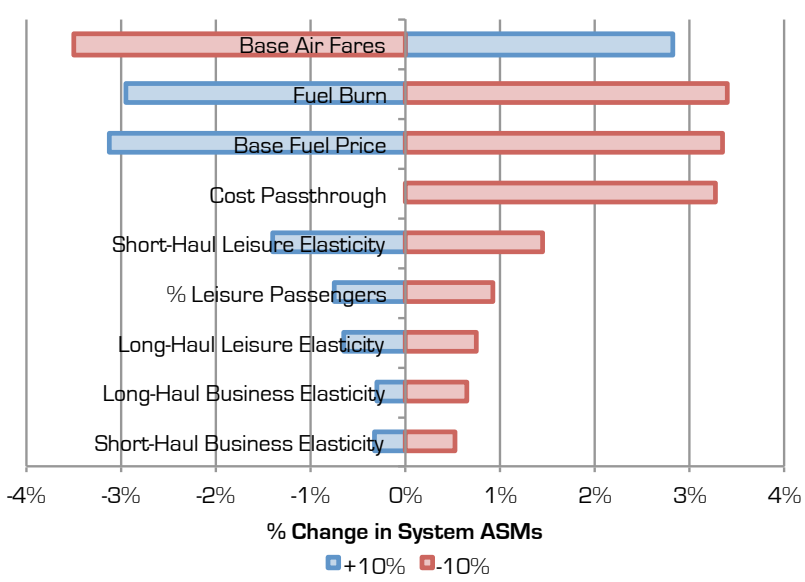

Figure 8 Sensitivity Analysis +100\% Fuel Price Scenario

\section{IMPLICATIONS FOR STAKEHOLDER POLICIES}

Given the expected impacts, how can industry stakeholders transition to higher fuel costs? This section explores potential policies to reduce loss of access to the air transportation system in small communities, to manage volatility in airport traffic, and to benefit from improving fleet fuel efficiency.

\section{Small Community Access}

Higher fuel costs are expected to cause reductions in service to small communities. Regional economic development is increasingly dependent on air transportation. Equitable air service that is operationally effective and economically efficient is a concern to nations worldwide (20). The U.S. has relied on the Essential Air Service (EAS) program to ensure small community access, but the cost of subsidies increased to $\$ 176$ million in 2010 .

The model was used to determine the additional direct subsidies that would be required in each fuel price scenario to maintain a minimum level of service at all EAS eligible airports to the nearest hub airport with the highest passenger flows in the base year. The additional subsidies required ranged from \$113-\$250 million in the $+50 \%$ scenario to $\$ 315-\$ 673$ million in the $+200 \%$ scenario. The ranges were dependent on the level of subsidized service - twice daily or four times daily round trips. It is uncertain whether governments would be willing to support this level of additional subsidies on top of their current commitments.

Nolan, Ritchie, and Rowcroft (21) examined various schemes to attract air service in small markets, including: direct subsidies, protected route packages, and guaranteed revenue approaches (e.g. airline travel banks). Using a small network simulation model, they evaluated each option in terms of social welfare and underlying agency costs. They found that using revenue guarantees, as opposed to direct subsidies, reduces the agency problems of adverse selection, opportunism and regulatory capture. Adverse selection occurs when communities lobbying for regulatory support have an inherent interest in overstating their need. Cases in which one or more of the parties abrogates the terms of an agreement demonstrate opportunism (e.g. an air carrier refusing to provide as many flights as originally promised). Regulatory capture results in the politician, the regulator, or the firm capturing the control and benefit of the regulatory process at the cost of the community. Therefore, economic efficiency may be improved if communities explore new means of ensuring their access to the air transportation system instead of relying on federal subsidies.

\section{Airport Traffic Volatility}

Airports are expected to experience greater traffic volatility as fuel costs increase, with smaller airports expected to experience the greatest volatility. Traffic volatility impacts the financial performance of airports as well as long-term planning and development as managers are no longer able to forecast future demand with certainty. de Neufville and Odoni (22) argue that flexibility must be incorporated in airport planning and development to ensure that airports are able to take advantage of growth opportunities while avoiding severe financial consequences if demand does not develop as forecasted. Incorporating flexibility in design enables airports to adjust to changes in the type, needs, and location of traffic. While airport planners previously worried about how fast traffic might grow, now they must also pay attention to where the traffic might grow, whether there will be abrupt and longlasting breaks in traffic (as can occur when an airline fails), and what kind of facilities future customers may need (23). Real options in airport design give the owner the right, but not the obligation, to take action now or in the future. Real options can enable a terminal to be quickly converted from domestic to international traffic or can rely on low-cost facilities to service high demand levels that require less debt to service if demand drops.

Airport planners must recognize the impact that volatile and increasing fuel prices will have on demand forecasts. Berardino and Spitz (24) developed a forecasting tool to assist airport planners in anticipating traffic changes due to external shocks. While the mean forecast may indicate long-term trends in traffic levels, uncertainty in the forecast is required to understand the 
expected volatility of future traffic when designing flexibility into airport plans.

Bonnefoy, de Neufville, and Hansman (25) reviewed the evolution of 59 multi-airport systems around the world and argued the need for multi-airport systems to meet future demand given the capacity constraints of existing major airports. Higher fuel costs may result in regional airport consolidation and a reduced need for multi-airport systems in major economic centers as system traffic levels drop. Air service may be consolidated at regional hubs, eliminating the need to maintain a disperse network of small airports. But in the United States there is the need to protect under-utilized airports due to the community opposition to expand existing airports or build green field airports. Existing airports may be viewed as options for future development and accommodation of air transport demand. This creates a tradeoff between the air transportation system's capacity needs now and in the future that decision makers must incorporate into system planning.

\section{Fleet Fuel Efficiency Improvements}

Improving the fuel efficiency of airline fleets will lessen the effects of fuel price increases and reduce the environmental impacts of aviation. While retrofits offer opportunities to reduce fuel burn in the near term, fleet renewal is the primary lever by which airlines can reduce their dependence on jet fuel by improving fleet efficiency. Fleet renewal is capital intensive and requires manufacturers to develop aircraft that have significant fuel efficiency improvements. For fleet renewal to be economical, the reductions in fuel and maintenance costs offered by new aircraft must be greater than the cost of capital invested in the new aircraft. Morrell and Dray (26) demonstrated that the substitution of new short/medium-haul aircraft for existing ones is not a cost-effective option for reducing fuel burn at oil prices that were assumed to rise from \$85 US\$ per barrel in 2010 to \$140 US\$ in 2025. Long-haul aircraft substitution was found to be more responsive due to the higher proportion of fuel costs in the total aircraft lifecycle costs.

While efficiency improvements would reduce airlines' operating costs, revenues would also be impacted if all savings were passed through to passengers (as assumed in this model). The simulation model was run to understand the impact of fuel efficiency improvements on airline revenues if all cost savings resulting from fuel efficiency improvements were passed on to passengers, as shown in Figure 9.

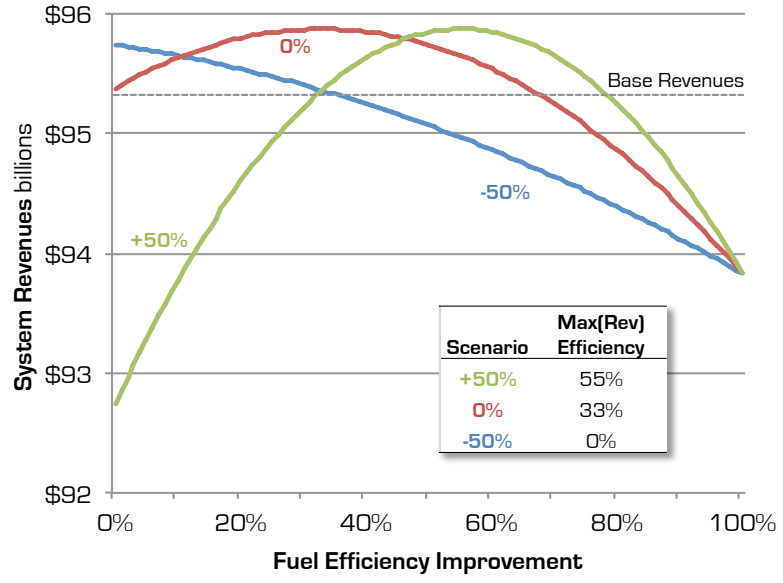

Figure 9 Impact of Fuel Efficiency Measures on System Revenues

While fuel efficiency improvements of $100 \%$ are not feasible in the foreseeable future, Figure 9 demonstrates that there is a tradeoff for airlines between: (1) additional revenue derived from increased traffic stimulated by reduced airfares, and (2) reduced revenue from lower average airfares. In the $-50 \%$ scenario, airlines have no revenue incentive to invest in fuel efficiency measures, as revenues are likely to drop due to lower airfares. In both the base case and the $+50 \%$ scenario, airlines do have revenue incentives to invest in fuel efficiency measures. Higher fuel prices offer greater incentives for fuel efficiency investments. These results show that airlines are likely to invest more aggressively in fuel efficiency improvements as fuel prices increase, but only if fuel cost savings from new aircraft exceed the cost of capital.

New commercial aircraft being developed in Japan, Canada, Russia, and China will increase competition for incumbent manufacturers. New competition may result in improvements to the performance of inproduction aircraft as well as the development of new, clean sheet design aircraft. But reduced demand for air transport will reduce the size of manufacturers' markets and may distort the relative size of aircraft market segments. Airlines may decide to maintain their frequency of service by using smaller aircraft or reduce their frequency of service and take advantage of the economies of scale of larger aircraft. These airline decisions will drive demand in aircraft market segments differently. Results from the model showed that aircraft with 50-199 seats generally saw relatively smaller reductions in ASMs than $250+$ seat aircraft, while aircraft in the 50-99 seat market segment are expected to experience the smallest reductions in ASMs. This model was limited by the constant fleet composition assumption, but may demonstrate that smaller aircraft flying in markets with higher yields are 
more profitable for airlines than large aircraft when faced with higher fuel costs.

\section{CONCLUSIONS}

Stakeholder action will be required to transition the U.S. air transportation system to higher fuel costs. A historical case study demonstrated the impact of the 2004-08 fuel price surge on the system. A simulation model was used to test the impacts of fuel price increases on the system with all other variables held constant. Although the results are dependent on the input variables and the structure of the model, they demonstrate that higher fuel costs will result in decreased traffic levels, decreased airline revenues, and increased traffic volatility at small airports. Governments, airports, airlines, and aircraft manufacturers will need to take action to mitigate the negative social and economic impacts of higher fuel costs. Policies to maintain access in small communities will ensure an equitable level of service but may require expensive direct subsidies if the current EAS program is maintained. Volatility in airport traffic levels will require flexibility to be built into airport planning. Fleet fuel efficiency improvements will reduce the sensitivity of the system to fuel cost increases but will require technology advances and airline access to capital. By gaining a greater understanding of the impacts of higher fuel costs on the U.S. domestic air transportation system, stakeholders can take action.

\section{ACKNOWLEDGMENTS}

The authors would like to thank William Spitz (GRA Inc.), Linda Howard, and Larry Goldstein (TRB), for their advice and mentorship throughout this project. Jan Vespermann provided the framework used to develop the air transportation system simulation model. MIT Partnership for AiR Transportation Noise \& Emissions Reduction (PARTNER) provided access to the Piano-X aircraft performance database. The Transportation Research Board's (TRB) Airport Cooperative Research Program (ACRP) supported this work through the Graduate Research Award Program on Public-Sector Aviation Issues.

\section{REFERENCES}

1. Boeing (2010). Current Market Outlook 2010 to 2029.

2. Lee, J., Lukachko, S., Waitz, I., and Schafer, A. (2001). Historical and Future Trends In Aircraft Performance, Cost, and Emissions. Annual Review Energy Environ, 26, 167-200.
3. International Air Transport Association (2009). A global approach to reducing aviation emissions. Switzerland.

4. Masschusetts et. al. v. Environmental Protection Agency, 05-1120 U.S. (2007).

5. Campbell, Colin J., and Jean H. Laherrère (1998). The End of Cheap Oil. Scientific American, Vol 278, Iss. 3, 78-83.

6. Energy Information Administration. (2011, April 26). Annual Energy Outlook 2011. Retrieved August 6, 2011, from http://www.eia.gov/forecasts/aeo/

7. Air Transportation Association (2011). ATA Monthly Jet Fuel Cost and Consumption Report. Cited April 8, 2011. URL:

http://www.airlines.org/Energy/FuelCost/Pages/Monthly JetFuelCostandConsumptionReport.aspx

8. Morrison, James K.D, Philippe A. Bonnefoy, R. John Hansman, and Sgouris Sgouridis (2010). Investigation of the Impacts of Effective Fuel Cost Increase on the US Air Transportation Network and Fleet. Presented at the $13^{\text {th }}$ American Institute of Astronautics and Aeronautics (AIAA) Aviation Technology, Integration, and Operations (ATIO) Conference, September 13-15 2010, Fort Worth, TX.

9. Office of Aviation Analysis. (2010). Essential Air Service Program. Cited June 16, 2010. URL: http://ostpxweb.dot.gov/aviation/x50\%20role files/essentialairservice.htm

10. Government Accountability Office (GAO) (2009). Commercial Aviation: Airline Industry Contraction Due to Volatile Fuel Prices and Falling Demand Affects Airports, Passengers, and Federal Government Revenues. GAO-09-393.

11. Tam, Ryan and R. John Hansman (2003). An Analysis of the Dynamics of the US Commercial Air Transportation System. S.M. thesis: Massachusetts Institute of Technology.

12. Vespermann, J., Bonnefoy, P.A., Hansman, R.J. (2010). Potential Impacts of US Climate Policy on the Airline Industry. Presented at the Aviation Transport Research Society (ATRS) Congress, July 2010, Portugal.

13. Bureau of Transportation Statistics (BTS) (2010). Form 41 Schedule T100 and DB1B 10\% Ticket Sample. URL: http://www.transtats.bts.gov/

14. Lissys. Piano-X. Aircraft Performance Database.

15. Gillen, David W., William G. Morrison, and Christopher Stewart (2008). Air Travel Demand Elasticities: Concepts, Issues and Measurement. Government of Canada, Department of Finance Canada.

16. JC Decaux (2011). US Airport Markets. Cited March 14, 2011. URL: http://www.jcdecauxna.com/airport/airportadvertising-locations

17. Yutko, Brian, Philippe A. Bonnefoy, Dmitri Mavris, et al. (2011). Assessment of $\mathrm{CO}_{2}$ Emission Metrics for a Commercial Aircraft Certification Requirement. Partnership for Air Transportation Noise \& Emissions Reduction.

18. Babikian, Raffi, Stephen P. Lukachko, Ian A. Waitz (2002). The historical fuel efficiency characteristics of regional aircraft from technological, operational, and cost perspectives. Journal of Air Transport Management 8, 389-400. 
19. Cento, A. (2009). The Airline Industry: Challenges in the 21st Century. Segrate, Italy: Physica-Verlag Heidelberg.

20. Metrass-Mendes, Alda and Richard de Neufville (2010). Air Transportation Policy for Small Communities: lessons from the U.S. Experience. 14th ATRS, July 6-9, 2010. Oporto, Portugal.

21. Nolan, James, Pamela Ritchie, and John Rowcroft (2005). Small Market Air Service and Regional Policy. Journal of Transport Economics and Policy, Vol. 39, Part 3, pp. 363-378.

22. de Neufville, Richard and Amadeo Odoni (2003). Airport Systems: Planning, Design, and Management. McGraw-Hill

23. de Neufville, Richard (2008). Low-Cost Airports for Low-Cost Airlines: Flexible Design to Manage Risks. Transportation Planning and Technology, Vol. 31, No. 1, pp. 35-68.

24. Berardino, Frank and William Spitz (2010). Impact of Jet Fuel Uncertainty on Airport Planning and Development Final Report. ACRP Transportation Research Board. ACRP 03-15.

25. Bonnefoy, Philippe A., Richard de Neufville, and R. John Hansman (2010). Evolution and Development of Multi-Airport Systems: A Worldwide Perspective. Journal of Transportation Engineering, 1021-1029.

26. Morrell, Peter and Lynnette Dray (2009). Environmental aspects of fleet turnover, retirement and life cycle. Omega, Cranfield University. 